\title{
APPLICATION OF BLOCKCHAIN TECHNOLOGIES FOR PROTECTION OF INTELLECTUAL PROPERTY
}

\begin{abstract}
Alla Dombrovska ${ }^{1}$
${ }^{1}$ Ph. D., Assistant Professor, Assistant Professor of the Department of Legal Support of Economic Activity, O.M. Beketov National University of Urban Economy in Kharkiv, Kharkiv, Ukraine, e-mail: dombrovskalla@gmail.com, ORCID: https://orcid.org/0000-0003-4610-8220

Abstract. Blockchain technology could be used to create and maintain any database or ledger that can record and track transactions and assets and can be widely accessible to the public or large groups, depending on the permissions granted. The aim of the article is to study the legal aspects of DL-technologies regarding intellectual property protection, IP-ownership, transfer of IPrights. The methodology of this study implies the use comparative analysis, the study of domestic and foreign researches, studying blockchain transformation processes of the law system in Ukraine on intellectual property. Considering the security, transparency, and immutable nature, blockchain can be applied for managing intellectual property (IP) rights such as patents, copyrights, trademarks, and industrial designs. The potential IP-related application of blockchain is verifying the authenticity of ownership. Due to its possibility to record, share, and synchronize transactions in its respective electronic ledgers, blockchain technology can be used as a platform where inventors can place their inventionsdigital works in the form of ledgers thereby acting as an intellectual property marketplace. The application of smart contracts has increased the utility of implementing blockchain to protect one's intellectual property.
\end{abstract}

Keywords: blockchain, intellectual property, copyright, ownership, smart contract

JEL Classification: C88, H11, K10, K19, K40

Formulas: 0; fig.: 0; tabl.: 0; bibl.: 13

Introduction. Blockchain technology could be used to create and maintain any database or ledger that can record and track transactions and assets and can be widely accessible to the public or large groups, depending on the permissions granted. The chain is updated with each transaction so that users can see the chronological activity for that blockchain. Once something is on the database, it cannot be removed. Due to its possibility to record, share, and synchronize transactions in its respective electronic ledgers, blockchain technology can be used as a platform where inventors can place their inventions/digital works in the form of ledgers thereby acting as an intellectual property marketplace.

Literature review. Today when digital technologies become more important, it is no longer possible to imagine our life without blockchain, a fault-tolerant decentralized system, the core principles of which are that each subsequent block in the blockchain contains the hash value of the previous block, and all attempts to change the data recorded on a particular block levels, will cause changes at all subsequent levels and will be noticed by other participants (network nodes). This ensures database integrity verification and a blockchain sequence is formed in which each subsequent block stores the hash value of the previous one [1,277].

Blockchain has gone far beyond cryptocurrencies, and has spread to all walks of life in society and the state, and thanks to its coordination capabilities and the ability to retain information has become a modern Magna Carta of fundamental social progress. The advantage of blockchain over other storage media is that the data that gets to it can be analyzed while remaining private and unchanged [2, 149-150]. 
Blockchain has prominent implications in various domains such as cryptocurrency, health care, real estate, voting systems, supply chain and logistics, etc. Theoretically, blockchain can be applied to any database and provide reliable storage of information. Considering the security, transparency, and immutable nature, blockchain can be applied for managing intellectual property (IP) rights such as patents, copyrights, trademarks, and industrial designs [3]. Implementing blockchain in the management of intellectual property have been developed in the works of: Miriam Stankovich [3], Sumit Prasad [4], Yuefei Caro, Hajme Nobuhara [5] and others.

Aim. The aim of the article is to study the legal aspects of DL-technologies regarding intellectual property protection, IP-ownership, transfer of IP-rights.

Methods. The methodology of this study implies the use comparative analysis, the study of domestic and foreign researches, studying blockchain transformation processes of the law system in Ukraine on intellectual property.

Results. According to the article 177 of the Civil Code [6] the results of intellectual, creative activity belong to the objects of civil rights and as it is enshrined in the article 199 of the Civil Code, the results of intellectual, creative activity and other objects of intellectual property rights create civil rights and obligations in accordance with Book IV of the Civil Code (intellectual property rights).

The potential IP-related application of blockchain is verifying the authenticity of ownership. In case of copyright, it is difficult to secure IP-ownership because of the lack of any official documentation, and the onus of proving ownership of a creative content lies with the creator. Exercising the copyright has become even more challenging in the era of internet, where anyone can download the content created such as a recorded song, a photograph, painting, etc. and can freely use it at will [4].

Proving the date of content creation is important in many situations and crucial for data used as evidence. For example, inventors must prove when exactly they put forward a patentable invention to obtain a patent. Trusted timestamping protocols, which rely on asymmetric cryptography, are used to prove that data has existed and has remained unaltered since a certain point in time [5].

Blockchain can be used to catalog and store original works. Often, there are no adequate means for authors to catalog their works and copyright ownership can be hard to prove. It can also be difficult for authors to see who is using their work, and it is equally difficult for third parties to know from whom to seek a license. Authors are often unable to stop infringements or to monetize their works successfully. With blockchain, copyrights need not be registered and can come into existence automatically upon the creation of original qualifying work.

Currently, IP owners have difficulties protecting the IP works online, i.e., once the IP work is uploaded on the internet, it becomes difficult to maintain control of that work and monitor who is using it for what purpose.

When the IP work is registered and verified using blockchain-based platforms, authors can search across a whole host of different sources simultaneously to ascertain who is using their work. This enables IP owners to identify and stop infringements and makes it easier to license their IP works. In this sense, blockchain 
can serve as an enforcement tool. With a blockchain-based registration system, verifying whether a new song is or isn't infringing upon the existing IP of a previously registered song will be much simpler. This type of blockchain-based detection system can be applied to text, art, and music with the help of artificial intelligence.

The addition of smart contracts has increased the utility of implementing blockchain to protect one's intellectual property. Smart contracts live on the blockchain and perform actions, such as allowing access to the information stored on the block, when conditions are met. By using this functionality, an owner can give licenses to users who want to access the intellectual property by accepting that user's digital signature. An owner can also deny a person access to their work this way. Smart contracts can also be utilized to collect royalties from people who are using and accessing intellectual property by establishing a contract.

The concept of smart contracts appeared in 1994, when cryptographer Nick Szabo concluded that with the help of an electronic decentralized register it was possible to conclude contracts that were executed automatically [7]. However, it became possible to implement this idea only in 2008, thanks to the advent of blockchain technology.

The development of the information economy causes such institutional problems of the society as the problem of trust, high costs of managing large amounts of information, risks of information attacks and the possibility of damage or loss of data due to various circumstances, including fraud, theft, or unauthorized use.

The potential of a decentralized approach and the use of such a consensus mechanism, in which the final state of the accounting system database is well protected from changes used in blockchain technology, enables accounting systems with multiple independent validators to achieve not only secure database synchronization but also data [1].

The innovation of this technology is that transactions are automatically verified and recorded by network nodes using cryptographic algorithms without human, government, or third-party intervention (banks, financial institutions, and any other organizations) [8].

O. Danilchenko believes that blockchain technology can be adapted to carry out any transactions, one way or another related to the registration, accounting, or transfer of various assets (financial, tangible and intangible); at the same time, neither the type, nor the number of participants, nor their geographical location matter [9].

Expanded capabilities of electronic communication and the latest technical and technological solutions have significantly changed business communication and caused the need to improve legal requirements. In 2015, as a result of amendments to Art. 205 of the Civil Code of Ukraine, the electronic form of the transaction was equated to the written one, and when it was made it became possible to use facsimile reproduction of the signature by mechanical or other copying, electronic numerical signature or other analogue of handwritten signature 207 of the Civil Code of Ukraine) [6]. The concept of electronic contract as an agreement of two or more parties aimed at establishing, changing, or terminating civil rights and obligations and 
executed in electronic form, is enshrined in paragraph 5 of Article 3 of the Law of Ukraine "On Electronic Commerce" [10].

Meanwhile, information technology made possible first electronic payments, and then led to the emergence in 2009 of "digital money" - cryptocurrency, as a special type of financial and payment asset, independent of the central banks of any country in the world, which exists exclusively in dematerialized (digital) form and provides complete anonymity of payment participants.

The digital environment of cryptocurrency circulation and its digital nature means that the application of a standard form of contract to transactions where it is a settlement instrument is undesirable. Today, such a tool is a smart contract.

Smart contract is a set of promises in digital format, including the protocol by which the parties fulfill these promises [7]. Smart contracts are agreements written in code that automatically perform programmed functions in response to certain conditions fulfilled by the parties to the agreement.

The elements of smart contracts include:

- subject of the contract. The program must have access to the goods and services that are the subject of the contract and be able to automatically provide or close this access to the counterparty.

- digital signatures. The parties certify the agreement with their own secret digital keys generated by a single technology

- the terms of the contract, set out in the exact sequence of operations, i.e., in the form of an algorithm, and agreed by the parties

- decentralized platform.

Recording, storage and enforcement of a smart contract takes place on a resource independent of the parties [7].

There is no definition of the concept of a smart contract in the legislation of Ukraine and the corresponding requirements to such contracts as well. It is necessary to agree with L. Mamchur and O. Nedybalyuk, who argue that it is impossible to consider a smart contract as a kind of contract concluded in electronic form, because, in accordance with paragraph 3 of Art. 3 of the Law of Ukraine "On Electronic Commerce", the electronic form of presentation of information is the documentation of information that allows it to be reproduced in a visual form suitable for human perception [11].

The basis of a smart contract is a transaction that is made via the Internet, and which can be qualified, according to paragraph 1 of Article 202 of the Civil Code of Ukraine, as an action of a person aimed at acquiring, changing, or terminating civil rights and obligations.

Discussion. Today, it is proposed to use smart contracts in a wide range of legal relationships, such as insurance, corporate acquisition of property, or for automatic payment for the delivery of goods or services. They are also especially recommended for the exchange of stocks, bonds, and options, as well as for microfinance services [12]. 
Blockchain and smart contracts can be used for licensing IP works by reducing the cost of transactions and creating a direct link between authors/inventors and users [3].

Smart contracts are agreements written in code that automatically perform programmed functions in response to certain conditions fulfilled by the parties to the agreement as a computer protocol, which based on mathematical algorithms translated into computer code, independently performs operations with full control over their execution. Using smart contracts, IP licenses can be self-executing upon the use of a work.

Smart contracts can also be used for micropayments for the use of content. The author could assign a Bitcoin address to an IP work, allowing the user to make a micropayment to the author in return for using the work. This system can eliminate the need for financial intermediaries and thus enable the author to be remunerated without paying the high transactions costs. The system also introduces simplicity and transparency in IP-related transactions.

Conclusions. Considering the security, transparency, and immutable nature, blockchain can be applied for managing intellectual property (IP) rights such as patents, copyrights, trademarks, and industrial designs. The potential IP-related application of blockchain is verifying the authenticity of ownership. Due to its possibility to record, share, and synchronize transactions in its respective electronic ledgers, blockchain technology can be used as a platform where inventors can place their inventionsdigital works in the form of ledgers thereby acting as an intellectual property marketplace. The application of smart contracts has increased the utility of implementing blockchain to protect one's intellectual property.

\section{References:}

1. Kravchenko P. Blokcheyn i detsentralizovannyie sistemyi [Blockchain and decentralized systems]: textbook for students of institutions of higher education: in 3 parts. Part 1 / P. Kravchenko, B. Scriabin, O. Dubinina. - Kharkov: PROMART, 2018 . - 408 p. : ill. 185; tab. 13; bibliography: 30 titles. (In Russian).

2. Swan Melanie. Blockchain: Blueprint for a New Economy / Melanie Swan - Sebastopol CA : O'Reilly Media, 2015. $-152 \mathrm{p}$.

3. Miriam Stankovich. Is Intellectual Property Ready for Blockchain? - [E-resource]. - Access mode: https://dai-globaldigital.com/is-intellectual-property-ready-for-blockchain.html

4. Sumit Prasad. The Future of Blockchain in Intelectual Property - [E-resource]. - Access mode: https://www.automation.com/en-us/articles/january-2021/the-future-of-blockchain-in-intellectual-property

5. Yuefei Caro, Hajme Nobuhara. A Decentralized Trusted Timestamping Based on Blockchain. - [E-resource]. Access

mode:

https://www.researchgate.net/publication/272359313 Decentralized Trusted Timestamping using the Crypto_Curren cy Bitcoin

6. Tsyvilnyi kodeks Ukrainy. Zakon Ukrainy vid 16 sichnia 2003 roku No 435-IV iz zm. i dop. URL: http://search.ligazakon.ua/l_doc2.nsf/link1/T030435.html

7. Szabo N. Smart Contracts: Building Blocks for Digital Markets / N. Szabo URL: http://www.alamut.com/subj/economics/nick_szabo/smartContracts.html

8. Atzori, M. (2017). Blockchain Technology and Decentralized Governance: is the State Still Necessary? Journal of Governance and Regulation, 6(1), 45-62. URL: https://virtusinterpress.org/IMG/pdf/10.22495_jgr_v6_i1_p5.pdf

9. Danil'chenko O. Blokchejn: yurist iz mashiny // YURIST\&ZAKON. 2017. № 21. June. URL: http://uz.ligazakon.ua/magazine_article/EA010438

10. Pro elektronnu komertsiiu. Zakon Ukrainy vid 03 veresnia 2015 roku No 675-VIII iz zm. i dop. // Vidomosti Verkhovnoi Rady Ukrainy. - 2015. - No45. - St.410

11. Mamchur L., Nedybaliuk O. Tsyvilno-pravovi realii dopustymosti vykorystannia smart-kontraktu u dohovirnykh vidnosynakh. Istoryko-pravovyi chasopys. 2018. No 2 (12). P. 90-94

12. Volodymyr Marchenko, Alla Dombrovska. On Determining the Legal Nature of Smart Contracts. Proceedings of the International Conference on Economics, Law and Education Research (ELER 2021) Advances in Economics, 
Business and Management Research. volume 170 p.175-179 Dordrecht, The Netherlands https://www.atlantispress.com/proceedings/eler-21/125954428.

13. Dombrovska, A. (2021). Blockchain and intellectual property. In International conference on Economics, Accounting and Finance. Retrieved from https://conf.scnchub.com/index.php/ICEAF/ICEAF-2021/paper/view/300

Received: November 29, 2021

Approved: December 24, 2021 